\title{
(2) OPEN ACCESS \\ Time before return to play for the most common injuries in professional football: a 16-year follow-up of the UEFA Elite Club Injury Study
}

\author{
Jan Ekstrand $\left(10,1,2\right.$ Werner Krutsch, ${ }^{3}$ Armin Spreco, ${ }^{4}$ Wart van Zoest, ${ }^{5}$ Craig Roberts, ${ }^{6}$ \\ Tim Meyer, ${ }^{7}$ Håkan Bengtsson
}

'Department of Medical and Health Sciences, Linköping University, Linköping, Sweden ${ }^{2}$ Aspetar Orthopaedic and Sports Medicine Hospital, Doha, Qatar

${ }^{3}$ Department of Trauma Surgery, Universitatsklinikum Regensburg, Regensburg, Germany

${ }^{4}$ Department of Medical and Health Sciences, Athletics Research Centre, Linköping University, Linköping, Sweden ${ }^{5}$ Department of Orthopaedic Surgery, St Anna Hospital, Eindhoven, The Netherlands ${ }^{6}$ AFC Bournemouth, Bournemouth, UK ${ }^{7}$ Institute of Sports and Preventive Medicine, University of Saarland, Saarbrücken, Germany

\section{Correspondence to}

Professor Jan Ekstrand Department of Medical and Health Sciences, Linköping University, Linköping S-582 21, Sweden;

jan.ekstrand@telia.com

Accepted 26 May 2019

Published Online First

10 June 2019

\section{ABSTRACT}

Objectives The objective was to describe the typical duration of absence following the most common injury diagnoses in professional football.

Methods Injuries were registered by medical staff members of football clubs participating in the Union of European Football Association Elite Club Injury Study. Duration of absence due to an injury was defined by the number of days that passed between the date of the injury occurrence and the date when the medical team allowed the player to return to full participation. In total, 22942 injuries registered during 494 team-seasons were included in the study.

Results The 31 most common injury diagnoses constituted a total of $78 \%$ of all reported injuries. Most of these injuries were either mild (leading to a median absence of 7 days or less, 6440 cases $=42 \%$ ) or moderate (median absence: $7-28$ days, $56 \%=8518$ cases) while only few ( $2 \%=311$ cases) were severe (median absence of $>28$ days). The mean duration of absence from training and competition was significantly different $(p<0.05)$ between index injuries and reinjuries for six diagnoses (Achilles tendon pain, calf muscle injury, groin adductor pain, hamstring muscle injuries and quadriceps muscle injury) with longer absence following re-injuries for all six diagnoses Conclusions The majority of all time loss due to injuries in professional football stems from injuries with an individual absence of up to 4 weeks. This article can provide guidelines for expected time away from training and competition for the most common injury types as well as for its realistic range.

\section{INTRODUCTION}

If a football player gets injured, the coaches' key question is usually as follows: 'When can he/she play again?"1 Given the economic and competitive implications associated with an absence of professional players, the time to return to trainings and/ or match play is of particular importance for the player as well as the club. ${ }^{2}$ The management of injuries benefits from an accurate prognosis for the return to play (RTP) in order to facilitate planning of future training and team composition. ${ }^{3}$ Medical and coaching staff face considerable pressure to enable the players' return to training sessions and matches as soon as possible. ${ }^{24}$

It has been recommended that decisions about the timing of RTP are criteria based but such an approach has proven to be problematic due to a lack of valid criteria ${ }^{35}$ with recurrences of injuries as a possible consequence of premature RTP. ${ }^{4}$ Therefore, evidence-based epidemiological information to guide a prognostic time loss estimation is potentially helpful for the medical staff to address questions from players, coaches, managers, media and agents regarding RTP.

RTP data from injury studies-the Elite Club Injury Study (ECIS) being the biggest of themcan provide some guidance for RTP decisions. ${ }^{8}$ The ECIS database contains 23000 time loss injuries from male professional football clubs in Europe. This material provides a wealth of information, for example, regarding the duration of absence from training and matches needed for certain injuries. $^{9}$

The objective of this study was to provide details about absence days and RTP for the 30 most common injuries in male elite level football, including data from both index injuries and re-injuries. Our hypothesis is that only a few diagnoses account for the majority of all injuries and that re-injuries have longer RTP compared with index injuries.

\section{MATERIALS AND METHODS}

This is a post hoc analysis of prospectively collected data from several cohorts of male professional football players. Data have been collected from professional football teams from the highest level of European professional football (Union of European Football Association ECIS), other European professional football teams with artificial turf installed at their home venue and the English, Swedish, Danish and Norwegian premiere divisions. In total, 116 teams from 24 countries have been followed over a varying number of seasons (1-16) between 2001 and 2017 adding up to a total of 494 team-seasons included in the present study. During this time, a total of 22942 injuries were reported with 19926 index injuries and 3016 re-injuries. The majority $(62 \%)$ of the included injuries were collected in the ECIS cohort while the other cohorts contributed with fewer cases $(13 \%$ from the Swedish premiere division, $10 \%$ from the artificial turf cohort, $9 \%$ from the English premiere division, 4\% from the Norwegian premiere division and $2 \%$ from the Danish premiere division). The same identical methodology has been used to collect data from all cohorts and detailed description of the study methodology ${ }^{9}$ and the included cohorts has been published previously. ${ }^{10-13}$ 


\section{Data collection}

Data from all cohorts have been collected using the same methodology in accordance with international consensus about how to conduct epidemiological studies in professional football. ${ }^{14}$ When teams were included in the study, they appointed contact persons from their medical staff who were responsible for collecting and reporting all necessary data during their study participation. All first team players from included clubs were invited to participate in the study and written and informed consent was collected from all players who chose to participate in the study.

Data about football exposure and injury occurrences were collected on an individual player level using the same standardised forms in all included clubs. Registered data were sent to the study group for review on a monthly basis. During this review process, members of the study group controlled all data to make sure that they were in accordance with study methodology.

Injury was defined, using a time-loss definition, as 'any physical complaint sustained by a player that results from a football match or football training and led to the player being unable to take full part in future football training or match play'. ${ }^{14} \mathrm{~A}$ player's period of absence following an injury constituted the full period (number of days) between the date when the player was forced to discontinue his football participation due to an injury until the date when the medical team allowed the player to return to full participation.

A re-injury was defined as an 'injury of the same type and location as a previous injury'. ${ }^{14}$

\section{Injury diagnosis}

The standardised injury forms contained information that described the nature of the reported injuries. First, the location and type of injury was described, in accordance with the previously mentioned consensus statement, ${ }^{14}$ using closed questions where the contact persons were instructed to choose from a number of options to describe the location and type of the reported injury (boxes $1 ; 2$ ). Second, contact persons were instructed to include a free-text diagnosis for all reported injuries. Based on this information, members of the study group assigned a standardised diagnosis to all reported injuries.

Box 1 Injury location options available on the standardised injury forms

Injury location
Head/face
Neck/cervical spine
Sternum/upper back
- Abdomen
Low back/pelvis
- Shoulder/clavicula
- Upper arm
- Elboarm
- Wrist
- Hand/finger/thumb
- Hip/groin
- Knigh
- Lower leg/Achilles tendon
- Foot/toe

Box 2 Injury type options available on the standardised injury forms
Injury type
- Concussion
- Lesion of meniscus/cartilage
- Haematoma/contusion/bruise
- Fracture
- Muscle rupture/strain
- Abrasion
- Other bone injury
- Tendon rupture/tendinosis
- Laceration
- Dislocation/subluxation
- Synovitis/effusion
- Nerve injury
- Sprain/ligament injury
- Overuse unspecified
- Dental injury
- Other injury

\section{Statistical analyses}

Index injuries and re-injuries were analysed separately and descriptive statistics were listed in one table each for the most common injury types. In all, 31 diagnoses were included in the index injury list (table 1) since there was an equal number of reported injuries for the 30th and the 31st most common diagnoses).

For each injury type, the number of injuries, the mean days of absence including the $95 \% \mathrm{CI}$, the median days of absence including the 95\% CI along with the 10th, 25th, 75th and 90th percentiles were calculated. The CI was calculated using the SD, along with the sample size and the appropriate $\mathrm{z}$-value from the standard normal distribution for the desired confidence level (for $95 \%$ CIs the $z^{*}$-value 1.96 is used). The formula is $95 \% \mathrm{CI}$ $= \pm \mathrm{Z}^{*} \times(\sigma / \sqrt{ } \mathrm{n})$, where $\sigma$ is the $\mathrm{SD}, \mathrm{n}$ is the sample size and $\mathrm{z}^{*}$ represents the appropriate $\mathrm{z}^{*}$-value from the standard normal distribution. The $95 \%$ CI for the median was calculated using the formulas $\mathrm{j}=\mathrm{n} \times \mathrm{m}-1.96 \times \operatorname{sqrt}(\mathrm{n} \times \mathrm{m}(1 \mathrm{~m}))$ for the observation of the lower limit and $\mathrm{k}=\mathrm{n} \times \mathrm{m}-1.96 \times \operatorname{sqrt}(\mathrm{n} \times \mathrm{m}(1 \mathrm{~m}))$ for the observation of the upper limit, where $n$ is the number of observations and $m$ is the median. The parameters $j$ and $k$ are rounded up to the next integer and the $95 \% \mathrm{CI}$ is found between the jth and the kth observations in the ordered data.

Re-injury rate was also included. The tables were sorted according to the median value, from the lowest to the highest value. If an injury type was represented in both the index injury table and the re-injury table, a Student's (independent) T-test was performed to decide if the mean days of absence significantly differed between the index injuries and the re-injuries.

The significance level for the $\alpha$-error was set at $p<0.05$. IBM SPSS Statistics (V.23.0) for Windows was used for all analyses.

\section{RESULTS}

Table 1 shows the length of absence for the most common index injuries. Mild injuries with absence below 7 days were mainly represented on the lower extremity by traumatic injury types like contusions or capsular and ligament injuries on the joints or overuse pain syndromes. Moderate ones were mainly structural muscles injuries on the thigh and groin-related pain syndromes, whereas the five injuries with longest absence were knee injuries (table 1). 
Table 1 Descriptive statistics regarding absence days for the 31 most common index injuries. The injuries are arranged according to their median absence

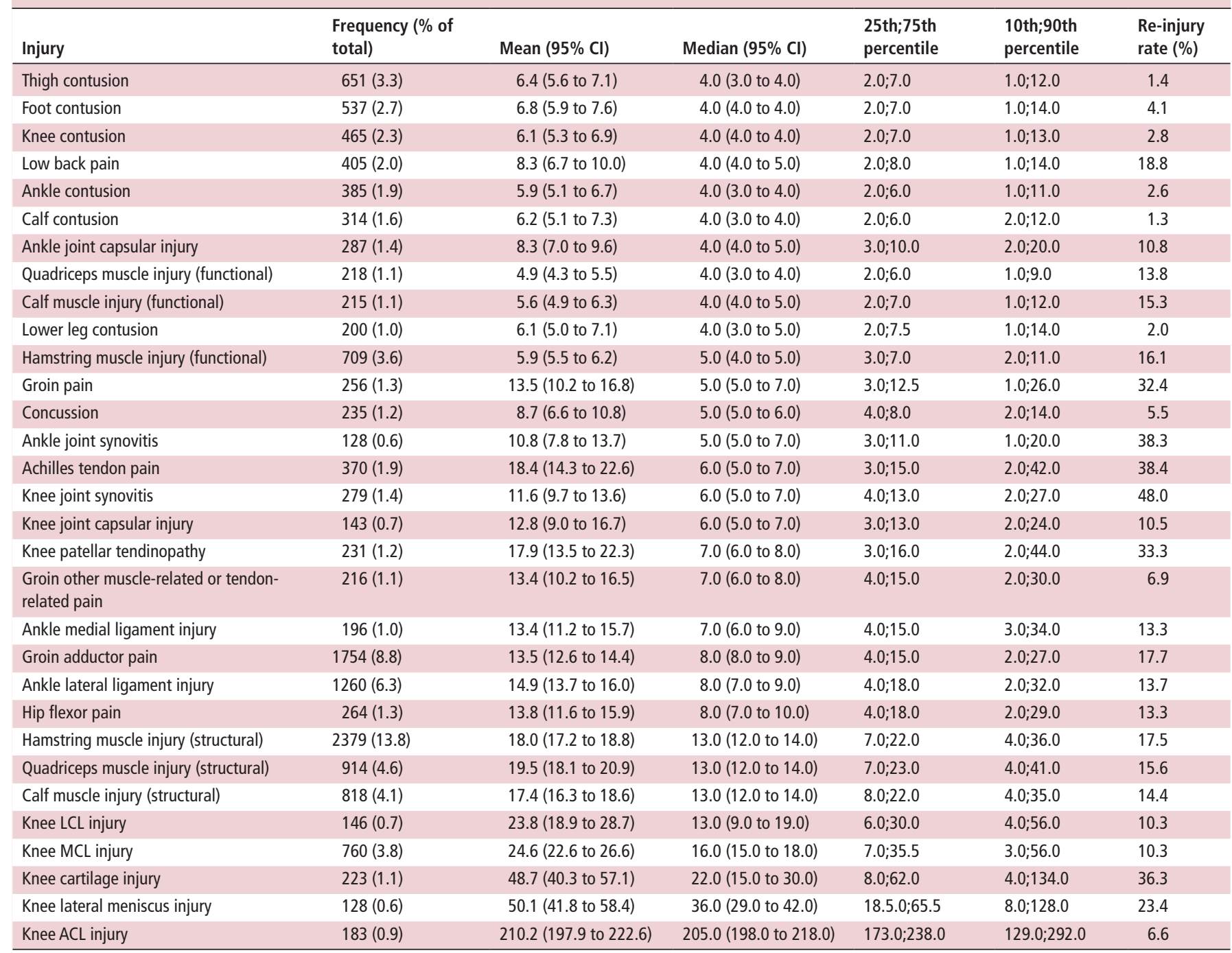

$\mathrm{ACL}$, anterior cruciate ligament; $\mathrm{LCL}$, lateral collateral ligament; $\mathrm{MCL}$, medial collateral ligament

The most common re-injuries showed a different pattern of types and a higher frequency of moderate injuries with absence of more than 7 days. While anterior cruciate ligament (ACL) injuries are missing among the 30 most common re-injuries, table 2 includes other injury types such as shoulder dislocation, lumbar disc injury or groin hernia, which were not common as index injury.

Table 2 shows the length of absence for the 30 most common re-injuries.

It was shown that the mean days of absence significantly differed between index injuries and re-injuries for only six injury types: Achilles tendon pain, calf muscle injury, groin adductor pain, functional and structural hamstring muscle injuries, and structural quadriceps muscle injury $(\mathrm{p}<0.05$ for all six injury types) (table 3 ). For all of them, the mean number of days of absence was longer for re-injuries than for index injuries, with the difference ranging from 3.3 (for calf muscle injury) to 10.6 (for Achilles tendon pain) days of absence.

\section{DISCUSSION}

The 31 most common injury diagnoses together are responsible for more than three-quarters of all injury-related time loss in professional football. This means that this study's data will give medical professionals useful prognostic information about when an injured player can be expected to be available for full participation in team activities again following the majority of all injuries that they will encounter. The study also shows that there are several diagnoses for which the absence following a re-injury is significantly longer than after an index injury highlighting the importance to avoid recurrences.

Mild injuries: potential to stay and play

Most of the 31 most common injury diagnoses are mild carrying a median absence of 7 days or less. Several of them may be considered 'stay-and-play' injuries meaning that players could suffer such an injury without being forced to miss a single game. ${ }^{15}$ Representatives of these mild injuries were contusions and joint injuries or pain syndromes of the lower extremity, which have good healing potential or show sufficient responsiveness to medical treatment within very few days. Due to such a limited period of absence these injuries, despite being common, will probably have limited impact on teams' performance and players' long-term health. One exception to this are concussions which may have long-lasting effects. ${ }^{16} 17 \mathrm{~A}$ second impact syndrome, that is a second blow to the head before symptoms from a prior concussion has been totally resolved, may have 
Table 2 Descriptive statistics regarding absence days for the 30 most common re-injuries. The injuries are arranged according to their median absence

\begin{tabular}{|c|c|c|c|c|c|}
\hline Injury & $\begin{array}{l}\text { Frequency (\% of } \\
\text { total) }\end{array}$ & Mean $(95 \% \mathrm{Cl})$ & Median $(95 \% \mathrm{Cl})$ & 25th;75th percentile & $\begin{array}{l}\text { 10th;90th } \\
\text { percentile }\end{array}$ \\
\hline Calf muscle injury (functional) & $33(1.1)$ & 7.3 (4.1 to 10.6$)$ & $4.0(2.0$ to 6.0$)$ & $2.0 ; 7.0$ & $2.0 ; 14.0$ \\
\hline Groin pain & $83(2.8)$ & $21.2(10.8$ to 31.5$)$ & $5.0(4.0$ to 8.0$)$ & $2.0 ; 16.0$ & $1.0 ; 56.0$ \\
\hline Low back pain & $76(2.6)$ & 12.7 (6.2 to 19.3$)$ & $5.0(4.0$ to 7.0$)$ & $3.0 ; 8.5$ & $2.0 ; 18.0$ \\
\hline Knee pain & $31(1.0)$ & $10.9(5.9$ to 16.0$)$ & $5.0(3.0$ to 9.0$)$ & $2.0 ; 10.0$ & $1.0 ; 27.0$ \\
\hline Knee joint synovitis & $134(4.4)$ & 13.8 (8.8 to 18.8$)$ & $6.0(4.0$ to 7.0$)$ & $2.0 ; 14.0$ & $1.0 ; 30.0$ \\
\hline Hamstring muscle injury (functional) & $114(3.8)$ & $9.2(7.1$ to 11.3$)$ & $6.0(5.0$ to 7.0$)$ & $3.0 ; 11.0$ & $2.0 ; 17.0$ \\
\hline Foot contusion & $22(0.7)$ & $11.8(0.5$ to 23.1$)$ & $6.0(2.0$ to 8.0$)$ & $2.0 ; 8.0$ & $1.0 ; 17.0$ \\
\hline Ankle lateral ligament injury & $173(5.7)$ & $12.9(10.3$ to 15.6$)$ & $7.0(5.0$ to 8.0$)$ & $3.0 ; 15.0$ & $2.0 ; 30.0$ \\
\hline Ankle joint synovitis & 49 (1.6) & 21.1 (3.8 to 38.4 ) & 7.0 (5.0 to 11.0$)$ & $3.0 ; 14.0$ & $2.0 ; 38.0$ \\
\hline Ankle medial ligament injury & $26(0.9)$ & 15.0 (9.5 to 20.5 ) & 9.0 (6.0 to 24.0$)$ & $6.0 ; 27.0$ & $3.0 ; 38.0$ \\
\hline Ankle pain & $20(0.7)$ & $17.0(7.1$ to 26.9$)$ & $11.0(4.0$ to 19.0$)$ & $3.5 ; 20.5$ & $1.0 ; 50.5$ \\
\hline Knee MCL injury & $78(2.6)$ & 27.0 (19.5 to 34.6$)$ & $13.0(9.0$ to 20.0$)$ & $7.0 ; 37.0$ & $4.0 ; 63.0$ \\
\hline Hip flexor pain & $35(1.2)$ & 16.6 (12.1 to 21.2$)$ & $13.0(6.0$ to 22.0$)$ & $6.0 ; 29.0$ & $2.0 ; 38.0$ \\
\hline Shoulder dislocation & $24(0.8)$ & 35.3 (14.6 to 56.1$)$ & $14.5(8.0$ to 32.0$)$ & $6.5 ; 47.0$ & $3.0 ; 100.0$ \\
\hline Hamstring muscle injury (structural) & $416(13.8)$ & 21.5 (18.9 to 24.1$)$ & $15.0(14.0$ to 17.0$)$ & $9.0 ; 25.0$ & $6.0 ; 40.0$ \\
\hline Quadriceps muscle injury (structural) & $143(4.7)$ & 23.7 (20.2 to 27.2$)$ & 16.0 (13.0 to 21.0$)$ & $9.0 ; 33.0$ & $4.0 ; 56.0$ \\
\hline Calf muscle injury (structural) & $118(3.9)$ & 20.8 (17.0 to 24.5$)$ & $16.0(14.0$ to 18.0$)$ & $9.0 ; 25.0$ & $5.0 ; 43.0$ \\
\hline Groin enthesiopathy/pubalgia & $44(1.5)$ & 35.9 (22.9 to 48.8$)$ & $17.0(10.0$ to 31.0$)$ & $8.0 ; 45.0$ & $4.0 ; 92.0$ \\
\hline Lumbar disc injury & $27(0.9)$ & 31.4 (18.4 to 44.4$)$ & $17.0(8.0$ to 42.0$)$ & $6.0 ; 45.0$ & $2.0 ; 78.0$ \\
\hline
\end{tabular}

MCL, medial collateral ligament.

serious consequences. ${ }^{18}$ To prevent repeated concussions in general, and the second impact syndrome in particular, a structured rehabilitation protocol has been developed. ${ }^{19}$ According to this protocol, and according to international consensus, ${ }^{17}$ athletes who have suffered a concussion should progress their activity level in a stepwise manner, without recurrent symptoms, over a minimum of 6 days before they are allowed to RTP. With this in mind, it is surprising that the median period of absence following a concussion in this cohort was only 5 days, meaning that at least $50 \%$ of the concussed athletes in this cohort RTP before the recommended minimum of 6 days of rehabilitation

Moderate injuries: the major cause of absence in professional football

Even though only nine of the 31 most common injuries were moderate, causing a median absence of 8-28 days, these together comprise more than $60 \%$ of all absence caused by the 31 most common injury diagnoses. This is partly due to their relatively long absence (in comparison to mild injuries) but mainly due to their high frequency. In fact, the six most frequent diagnoses (hamstring muscle injury (structural), groin adductor pain, ankle lateral ligament injury, quadriceps muscle injury (structural), calf muscle injury (structural) and knee medial collateral ligament injury) all belonged to the moderate category and comprised more than $50 \%$ of all absence caused by the 31 most common injury diagnoses. Structural muscle injuries to the calf muscles, hamstrings and quadriceps were all included among these six most common diagnoses with very similar periods of absence (median 13 days absence for all muscle groups). This might indicate that muscle tissue needs a certain amount of time for its biological healing process to occur before players are able to RTP after structural damage regardless of which muscle group is affected.

Severe injuries: potential long-term effects for the athletes Severe injury diagnoses were shown to be quite uncommon with only two of the 31 most common injury diagnoses causing a median absence of more than 28 days, ACL tears and lateral meniscus injury. ACL ruptures, in particular, stand out with a median absence of 205 days (95\% CI: 198 to 218 days). Even though ACL rupture is the diagnosis with the longest absence among common football injury diagnoses, the median RTP is still shorter than the 9-12 months that have been recommended in a recent publication. ${ }^{20}$ In fact, less than $15 \%$ of the players suffering an ACL injury in the current cohort (25 out of 183 ACL injuries) had a period of absence exceeding 9 months (270 days).

While being relatively infrequent, severe injuries still have the potential to heavily impact on teams' player availability due to their long absence associated. The two severe injury 
Table 3 Differences in days absence between index and re-injuries (only if the injury type occurs for both index injuries and re-injuries). Differences exist if $p<0.05$

\begin{tabular}{lcl}
\hline Injury & Mean difference $(95 \%$ Cl) & $\begin{array}{l}\mathbf{P} \\
\text { value }\end{array}$ \\
\hline Achilles tendon pain & $-10.6(-20.6$ to -0.6$)$ & $0.037^{*}$ \\
\hline Ankle joint capsular injury & $-5.2(-15.3$ to 5.0$)$ & 0.307 \\
\hline Ankle joint synovitis & $-10.4(-28.3$ to 7.6$)$ & 0.252 \\
\hline Ankle lateral ligament injury & $1.9(-1.3$ to 5.2$)$ & 0.244 \\
\hline Ankle medial ligament injury & $-1.6(-8.1$ to 5.0$)$ & 0.642 \\
\hline Calf muscle injury (functional) & $-1.8(-5.2$ to 1.7$)$ & 0.304 \\
\hline Calf muscle injury (structural) & $-3.3(-6.6$ to 0.0$)$ & $0.047^{*}$ \\
\hline Foot contusion & $-5.0(-16.4$ to 6.3$)$ & 0.367 \\
\hline Groin adductor pain & $-5.7(-9.5$ to -1.8$)$ & $0.004^{*}$ \\
\hline Groin pain & $-7.7(-18.7$ to 3.3$)$ & 0.169 \\
\hline Hamstring muscle injury (functional) & $-3.4(-5.5$ to -1.2$)$ & $0.003^{*}$ \\
\hline Hamstring muscle injury (structural) & $-3.6(-6.3$ to -0.9$)$ & $0.010^{*}$ \\
\hline Hip flexor pain & $-2.9(-9.0$ to 3.3$)$ & 0.360 \\
\hline Knee cartilage injury & $-20.6(-41.7$ to 0.6$)$ & 0.056 \\
\hline Knee joint synovitis & $-2.1(-7.5$ to 3.3$)$ & 0.435 \\
\hline Knee lateral meniscus injury & $-10.5(-30.3$ to 9.2$)$ & 0.293 \\
\hline Knee MCL injury & $-2.5(-9.2$ to 4.2$)$ & 0.472 \\
\hline Knee patellar tendinopathy & $-4.2(-14.0$ to 5.5$)$ & 0.393 \\
\hline Low back pain & $-4.4(-11.3$ to 2.5$)$ & 0.208 \\
\hline Quadriceps muscle injury (functional) & $-1.5(-3.6$ to 0.6$)$ & 0.168 \\
\hline Quadriceps muscle injury (structural) & $-4.2(-8.0$ to -0.4$)$ & $0.031^{*}$ \\
\hline Signicant diffence &
\end{tabular}

${ }^{*}$ Significant difference in days absence between index and re-injuries $(p<0.05)$.

$\mathrm{MCL}$, medial collateral ligament.

diagnoses together caused 18\% of all absence days from all 31 most common diagnoses. This highlights the importance to not only consider injury frequency when evaluating consequences of injuries in professional football. The combination of injury frequency and severity, that is, the injury burden, will most likely be a more clinically viable tool to describe the impact of injuries in professional football teams. ${ }^{21}$

\section{Re-injuries: extended absence compared to index injuries}

When analysing re-injury rates, it became evident that there were some diagnoses for which the re-injury rate was lower than expected while several diagnoses carried a relatively high re-injury rate. One of these diagnoses was ACL injury which had a re-rupture rate of only $6.6 \%$ in our population. This is lower than what has been previously shown in athletes returning to their prior sports level. ${ }^{22}$ The fact that the absence period following an ACL injury in this cohort is relatively short and that the re-rupture rates are still relatively low may be seen as a sign that the management of these injuries at the professional level of European football is effective and successful in many cases.

The mean absence following re-injuries was numerically longer than after index injuries for all but one of the 21 diagnoses that were included from the most common diagnoses for both re-injuries and index injuries. This difference was statistically significant for six diagnoses (Achilles tendon pain, calf muscle injury (structural), groin adductor pain, hamstring muscle injury (functional), hamstring muscle injury (structural) and quadriceps muscle injury (structural)) highlighting the importance to avoid re-injuries. The RTP decision is, however, very complex and several different factors must be considered. ${ }^{23}$ It has already been argued that aiming for the lowest level of risk for re-injuries may not always be possible in practice, especially in an elite environment. ${ }^{24}$ In addition, the RTP decision often has to be made without scientific evidence about useful criteria or about a typical duration of absence following different injuries. This means that such decisions in many cases will rely mainly on the experience of the responsible medical personnel. ${ }^{25}$ One possible explanation why the absence after re-injuries was longer compared with the respective index injuries for several diagnoses in the present study could be that the RTP decision following re-injuries was made considering the fact that the players had already suffered re-injuries and that the recommended period of absence therefore was extended to avoid additional re-injuries.

In addition, the majority of the six re-injury diagnoses that caused significantly longer absence compared with index injuries was different muscle injury diagnoses. A study by Kouloris et $a l^{26}$ has previously shown more structural muscle damage when re-injuries were compared with their index injuries which also could potentially explain the extended period of absence after re-injuries. However, contrasting results with similar amount of muscle damage between re-injuries and index injuries have been published, too. ${ }^{27}$

\section{Methodological considerations}

This study had several strengths. The main strength was the substantial dataset, which comprised a homogeneous group of male professional footballers. In addition, the study methodology follows international consensus about how to conduct epidemiological research in football. ${ }^{14}$ This potentially makes it a reliable and useful tool for evaluating injury risk and injury patterns in elite male footballers.

It should, however, be acknowledged that the results are based on data gathered at the highest level of European professional football which means that it is plausible that the injured athletes in this cohort are provided with the best possible care including immediate diagnoses and, in many cases, tailor-made rehabilitation supervised by personal physiotherapists. The absence days presented in this paper should therefore be considered as ones that can be expected only under best case scenarios while it is possible that the different diagnoses would cause longer periods of absence in other cohorts such as in lower level football. It should also be acknowledged that it might not always be in the athletes' best interest to aim at the shortest possible absence after an injury as it might increase the risk of re-injury as shown by Gajhede et al. ${ }^{6}$ It must finally be acknowledged that the absence data presented in the present study should merely be used as prognostic information and not as time-based RTP criteria.

The focus of this study has been the median absence rather than the mean and for some diagnoses the difference between the two is large, for example, for Achilles tendon pain that had a mean absence of 18.4 days while the median absence was only 6 days. The mean is normally used for data that follow a normal distribution and is largely influenced by outliers, while median is better suited for skewed distributions to derive at central tendency since it is much more robust. Since the data we analyse were skewed, the median is superior to the mean when analysing expected absence and is therefore used as the main central tendency value in this study.

However, we also included means along with the 95\% CIs in tables 1 and 2 . In theory, the $95 \%$ CI means that if we were to take 100 different samples of data and computed a 95\% CI for each sample, then approximately 95 of the 100 CIs would contain the true mean value. The SD is a measure of how much the different observations of a sample deviate on average from the sample mean. The reason why we show the mean along with 
the $\mathrm{CI}$ and not the SD in tables 1 and 2 is because the first gives us information about the true mean for the entire population and not only information about this particular sample.

\section{What are the findings?}

- Most injury absences in professional football is attributed to few mild and moderate injury diagnoses.

- Severe injuries, causing a median absence of more than 28 days, are infrequent.

- The length of the absence following re-injuries is significantly longer compared with the one after index injuries for several injury diagnoses.

- Mean absence time after concussion is surprisingly short when compared with available international recommendations.

\section{How might it impact on clinical practice in the future?}

- These data will provide clinicians with prognostic information about expected length of the absence following the majority of all injuries in professional football.

Acknowledgements The authors wish to thank all participating clubs, including all coaches, players and medical staff for their participation and contribution to the study.

Contributors JE was responsible for the conception and design of the study. JE and AS conducted the analyses which were planned and checked with the remaining authors. All authors contributed to the interpretation of the findings. JE wrote the first draft of the paper which was then critically revised and approved by all authors. JE is the study guarantor.

Funding The Football Research Group was established in Linkoping, Sweden, in cooperation with Linkoping University. It was supported by grants from UEFA, the Swedish Football Association, and the Swedish Research Council for Sport Science.

Competing interests TM work was partly sponsored by Saarland University and the German Football Association (DFB) via grants for the international PhD programme "Science and Health in Football".

Patient consent for publication Not required.

Ethics approval Written and informed consent was collected from all participating players. The study design was approved by the UEFA Football Development Division and the UEFA Medical Committee.

Provenance and peer review Not commissioned; externally peer reviewed.

Data availability statement No data are available.

Open access This is an open access article distributed in accordance with the Creative Commons Attribution Non Commercial (CC BY-NC 4.0) license, which permits others to distribute, remix, adapt, build upon this work non-commercially, and license their derivative works on different terms, provided the original work is properly cited, appropriate credit is given, any changes made indicated, and the use is non-commercial. See: http://creativecommons.org/licenses/by-nc/4.0/.

ORCID iDs

Jan Ekstrand http://orcid.org/0000-0002-6092-266X

Håkan Bengtsson http://orcid.org/0000-0003-3809-5909

\section{REFERENCES}

1 Ekstrand J. Preventing injuries in professional football: thinking bigger and working together. Br I Sports Med 2016;50:709-10

2 Cohen SB, Towers JD, Zoga A, et al. Hamstring injuries in professional football players: magnetic resonance imaging correlation with return to play. Sports Health 2011:3:423-30
3 Comin J, Malliaras P, Baquie P, et al. Return to competitive play after hamstring injuries involving disruption of the central tendon. Am J Sports Med 2013;41:111-5.

4 Ekstrand J, Healy JC, Waldén $M$, et al. Hamstring muscle injuries in professional football: the correlation of MRI findings with return to play. Br J Sports Med 2012:46:112-7.

5 Orchard J, Best TM, Verrall GM. Return to play following muscle strains. Clin J Sport Med 2005:15:436-41.

6 Gajhede-Knudsen M, Ekstrand J, Magnusson H, et al. Recurrence of Achilles tendon injuries in elite male football players is more common after early return to play: an 11-year follow-up of the UEFA champions League injury study. Br J Sports Med 2013:47:763-8.

7 Ekstrand J, Hägglund M, Kristenson K, et al. Fewer ligament injuries but no preventive effect on muscle injuries and severe injuries: an 11-year follow-up of the UEFA champions League injury study. Br J Sports Med 2013;47:732-7.

8 Hallén A, Ekstrand J. Return to play following muscle injuries in professional footballers. J Sports Sci 2014;32:1229-36.

9 Hägglund $M$, Waldén $M$, Bahr R, et al. Methods for epidemiological study of injuries to professional football players: developing the UEFA model. Br J Sports Med 2005;39:340-6.

10 Ekstrand J, Waldén M, Hägglund M. Hamstring injuries have increased by 4\% annually in men's professional football, since 2001: a 13-year longitudinal analysis of the UEFA Elite Club injury study. Br J Sports Med 2016:50:731-7.

11 Ekstrand J, Hägglund M, Waldén M. Epidemiology of muscle injuries in professional football (soccer). Am J Sports Med 2011;39:1226-32.

12 Hägglund M, Waldén M, Ekstrand J. Injury incidence and distribution in elite football-a prospective study of the Danish and the Swedish top divisions. Scand J Med Sci Sports 2005;15:21-8

13 Kristenson K, Bjørneboe J, Waldén M, et al. The Nordic football injury audit: higher injury rates for professional football clubs with third-generation artificial turf at their home venue. Br J Sports Med 2013;47:775-81.

14 Fuller CW, Ekstrand J, Junge $A$, et al. Consensus statement on injury definitions and data collection procedures in studies of football (soccer) injuries. Br J Sports Med 2006:40:193-201.

15 Krutsch W, Eder K, Krutsch V, et al. ["Stay and play" in football : Art of keeping players fit to play]. Unfallchirurg 2018;121:433-40.

16 Nordström A, Nordström P, Ekstrand J. Sports-related concussion increases the risk of subsequent injury by about $50 \%$ in elite male football players. Br J Sports Med 2014; 48:1447-50.

17 McCrory P, Meeuwisse W, Dvořák J, et al. Consensus statement on concussion in sport-the $5^{\text {th }}$ international conference on concussion in sport held in Berlin, October 2016. Br J Sports Med 2017;51:838-47.

18 McLendon LA, Kralik SF, Grayson PA, et al. The controversial second impact syndrome: a review of the literature. Pediatr Neurol 2016;62:9-17.

19 Aubry M, Cantu R, Dvorak J, et al. Summary and agreement statement of the first International Conference on concussion in sport, Vienna 2001. Recommendations for the improvement of safety and health of athletes who may suffer concussive injuries. Br J Sports Med 2002;36:6-10

20 van Melick N, van Cingel REH, Brooijmans F, et al. Evidence-based clinical practice update: practice guidelines for anterior cruciate ligament rehabilitation based on a systematic review and multidisciplinary consensus. Br J Sports Med 2016;50:1506-15.

21 Bahr R, Clarsen B, Ekstrand J. Why we should focus on the burden of injuries and illnesses, not just their incidence. Br J Sports Med 2018;52:1018-21.

22 Grindem H, Snyder-Mackler L, Moksnes H, et al. Simple decision rules can reduce reinjury risk by $84 \%$ after $A C L$ reconstruction: the Delaware-Oslo $A C L$ cohort study. $\mathrm{Br}$ J Sports Med 2016:50:804-8.

23 Dijkstra HP, Pollock N, Chakraverty R, et al. Return to play in elite sport: a shared decision-making process. Br J Sports Med 2017;51:419-20.

24 McCall A, Lewin C, O'Driscoll G, et al. Return to play: the challenge of balancing research and practice. Br J Sports Med 2017;51:702-3.

25 Ardern CL, Glasgow P, Schneiders A, et al. 2016 consensus statement on return to sport from the first World Congress in sports physical therapy, Bern. Br J Sports Med 2016:50:853-64

26 Koulouris $\mathrm{G}$, Connell DA, Brukner $\mathrm{P}$, et al. Magnetic resonance imaging parameters for assessing risk of recurrent hamstring injuries in elite athletes. Am J Sports Med 2007:35:1500-6.

27 Wangensteen A, Tol JL, Witvrouw E, et al. Hamstring Reinjuries occur at the same location and early after return to sport: a descriptive study of MRI-Confirmed Reinjuries. Am J Sports Med 2016:44:2112-21. 